\title{
A high triglyceride/ high-density lipoprotein ratio is associated with an increased risk of insulin resistance in the US population: a cross-sectional study from the US National Health and Nutrition Examination Survey, 2017-2018
}

\section{Rongpeng Gong ( $\sim 7728955 @ q q . c o m)$}

Qinghai Medical College: Qinghai University Medical College https://orcid.org/0000-0003-1117-0956

Zheng Li

Qinghai Medical College: Qinghai University Medical College

Ya Liu

Qinghai Medical College: Qinghai University Medical College

\section{Gang Luo}

Qinghai Medical College: Qinghai University Medical College

Lixin Yang

Qinghai Provincial People's Hospital

Xiaoxing Wei

Qinghai Medical College: Qinghai University Medical College

Original investigation

Keywords: Triglyceride to high-density lipoprotein cholesterol ratio, HDL-C, insulin resistance, Prediction

Posted Date: January 28th, 2021

DOl: https://doi.org/10.21203/rs.3.rs-154501/v1

License: () (i) This work is licensed under a Creative Commons Attribution 4.0 International License. Read Full License 


\section{Abstract}

Background Some previous studies have reported that the ratio of triglycerides to high-density lipoprotein may indicate insulin resistance, but the results suggest that there are differences between different ethnic groups. In this study, the NHANES 2017-2018 database was used to explore the relationship between TG/HDL-C and IR in the American population. Methods This trial comes from a cross-sectional study of NHANES ( http://www.cdc.gov/nchs/nhanes/ ) conducted by the National Center for Health Statistics (NCHS) of the US Centers for Diseases and Control and Prevention. IR uses the homeostatic model assessment (HOMA) formula as an indicator: [fasting insulin $(\mu \mathrm{U} / \mathrm{mL}) \times$ fasting blood glucose $(\mathrm{mmol} / \mathrm{L})] / 22.5$, with $\geq 75$ th percentile of HOMA-IR as an indicator. Use logistic regression to explore the relationship between TG/HDL ratio and IR occurrence. Results In this study, a total of 450 participants $(40 \%, 450 / 1902)$ developed insulin resistance. Using logistic regression model of the association between TG/HDL-C and insulin resistance risk, after adjusting for potential confounding factors, as the TG/HDL ratio increases, the probability of insulin resistance increases significantly (OR: 1.91, 95\% Cl: 1.59-2.30, P<0.0001). At the same time, we performed a smooth curve fitting and found a non-linear relationship between TG/HDL and IR. Even if the adjusted covariate is deleted from the model, the association remains unchanged. The smooth curve of TG/HDL-C The inflexion point is 0.95 . When TG/HDL-C $<0.95$, the effect value is very significant (OR: $27.34,95 \% \mathrm{Cl}, 10.61-70.47, \mathrm{P}<0.0001$ ), when TG/HDL-C $\geq 0.95$, the effect value is relatively reduced (OR: 1.29, 95\% Cl, 1.03-1.61, $\mathrm{P}<0.0001$ ). We grouped them by inflexion points. Multiple regression equations showed that after adjustment, the group's risk of insulin resistance greater than 0.95 increased by two times compared with the group less than 0.95 . Conclusions In this study, we found that the increase of TG/HDL-C ratio in the American population was significantly related to IR. It is clinically acceptable and can save some extra costs for patients. However, in different situations, combining the TG/HDL-C ratio with other risk factors to predict whether IR will occur is worthwhile for the next step.

\section{Introduction}

Insulin resistance is the insensitivity to insulin in insulin-dependent organ tissues. Its clinical manifestation is nonresponse to the sugar load, which leads to the metabolic disorder of fat, protein, and other carbohydrates in the body.

Previous studies have shown that metabolic disorders can cause systemic toxicity and chronic diseases such as thrombosis, oxidative peroxidation, endothelial dysfunction, even they can cause diabetes in severe cases. In a 2014 study (1), Paul Welsh et al. found that older adults without insulin resistance had a much lower incidence of diabetes than those with insulin resistance. At the same time, another 13-year follow-up study (2) showed that patients with insulin resistance also had a significantly increased risk of cardiovascular disease. Gianluca et al. (3) conducted a 15-year cohort study analysis. They found that patients' mortality rate with insulin resistance was significantly different from those irrelevant to it in cancer cases. The mortality rate of cancer patients with insulin resistance was $5.6 \%$ higher than that of patients without insulin resistance. Therefore, insulin resistance (IR) can be considered a predictor of diabetes mellitus (DM), cardiovascular disease, and tumour. 
As awareness of IR increases, we find that obesity often accompanies insulin resistance. Besides, smoking, hyperlipidemia, and hypertension have been affirmed and widely recognized as common risk factors for insulin resistance (IRRF). In Europe, a study of children found a $10.9 \%$ incidence of IR (4), suggesting that IR may occur with unrecognized IRRFs. Therefore, it is essential to find a model that can reduce the occurrence rate of IR.

At present, there are several methods to make a primary diagnosis of IR directly or indirectly (5). The gold standard diagnostic method is the high insulin regular blood sugar clamp test (HEC test), which is initially developed by DeFronzo(6). However, it is apparent defects, like high cost, fearful invasion, and long time required, so this method is not yet feasible in the clinical application (7).

Therefore, an easy mark of predicting IR helps clinicians identify whether patients have IR at an early stage and save patients' costs. Some studies have found that high triglyceridemia and low-density lipoprotein cholesterol plays a critical role in IR $(8,9)$, concluding the triglyceride/high-density lipoprotein cholesterol ratio as a simple clinical indicator of IR and a predictor of diabetes and coronary heart disease $(10,11)$. Various studies of potential clinical uses of triglyceride/HDL cholesterol ratios in adults and children have recently been investigated. Based on commonly used standardized measurements, the TG/HDL-C ratios index helps clinicians identify IR patients $(10,12-22)$. Based on data from the 2017-2018 National Health and Nutrition Examination Survey (NHANES), our study explored the role of the TG/HDL-C ratio in predicting IR in the general population. It suggests that early TG/HDL-C monitoring is of great significance in preventing insulin resistance and reducing the occurrence of chronic diseases related to insulin resistance.

\section{Methods}

\section{Study design and study population}

This trial comes from the CDC's National Center for Health Statistics (NCHS) cross-sectional study of NHANES(http://www.cdc.gov/nchs/nhanes/). Based on an intricate, layered, multistage probabilistic design, NHANES obtained a nationally representative sample of noninstitutionalized residents of the United States (23). The NHANES program began in the early 1960 s as a series of surveys of different populations or health topics. The NHANES study program is described in detail elsewhere (National Center for Environmental Health, Centers for Disease Control and Prevention). The NHANES protocol has been reviewed and approved by the NCHS Research Ethics Committee. All participants provided written informed consent before participation. The survey is unique in its combination of interviews and medical examinations. In this study, a total of 9,254 subjects participated in THE NHANES during 2017-2018. Of those, 1,810 were excluded for lack of HIGH-density lipoprotein test information. Secondly, 1034 subjects were further excluded due to lack of routine laboratory examination information, 4499 subjects were further excluded due to lack of insulin, and a total of 1,902 subjects participated in this trial. These potential confounders were chosen on the basis of previous scientific literature, or a more than $10 \%$ change in effect estimates.

\section{Data collection and measurement}


Uniformly trained investigators collect all the information. These data include demographic data (gender, age, race/ethnicity, etc.), health-related behaviours (smoking and drinking), anthropometric measurements (such as height, waist circumference, weight, etc.), and biochemical tests (TC, TG, GLU, etc.). Insulin was determined using the AIA-PACK method on the Tosoh AIA System Analyzer. Subjects' height, weight, and WC were measured according to standardized protocols and techniques. $\mathrm{BMI}$ is calculated as follows: $\mathrm{BMI}=$ weight $(\mathrm{Kg}) /$ height $\left(\mathrm{M}^{2}\right)(25)$. BMl cutoff point. Normal $\left(18.5 \sim 24.9 \mathrm{~kg} / \mathrm{m}^{2}\right)$, overweight $\left(25.0 \sim 29.9 \mathrm{~kg} / \mathrm{m}^{2}\right)$, obese $\left(B M I \geq 30.0 \mathrm{~kg} / \mathrm{m}^{2}\right)$.IR is defined by values equal to or greater than the 75 th percentile. In this study, the value is 4.4 , which represents the diagnostic value of IR to the study population as a whole rather than the general sample.

\section{Assessment criteria}

In this study, we classified smoking status into three levels. Never Smoker: Defined as having never smoked a cigarette in one's life or having smoked less than 100 cigarettes in total. Because the numbers are so small, we reduced quitters to never smokers. Recent nonsmokers smoked more than 100 cigarettes and smoked less than one cigarette per day for 30 days on average. Recent smokers had more than 100 cigarettes and an average of more than one cigarette per day for 30 days.

\section{hypertension}

Personal interview questionnaires were administered to NHANES participants to collect data on their knowledge, treatment, and hypertension control. This study defined patients who reported that they had hypertension and were taking antihypertensive drugs as hypertensive patients.

\section{Statistical analysis}

To make the samples more representative, we adopted the NHANES database, which has a complex, multistage probability sampling design. It looked at a nationally representative sample; Each year, 5,000 people were selected from a sampling framework of 15 different locations from all US counties. IR prevalence is a weighted percentage of IR in a complex sample, equal to the number of IR patients divided by the total number of IR patients. R 3.4.3 version was used for statistical analysis. Continuous variables are represented as detailed sample descriptions with averages and a $95 \%$ confidence interval. Categorical variables are represented by counts and weighted percentages, using complex sample frequencies. Continuous variables between groups were compared using student T-test or Mann-Whitney U test based on distributed normality, and classified variables were compared using the Fisher exact test. Since TG/HDL is a continuous variable, we used the generalized additive model (GAM) to identify the non-linear relationship and found that TG/HDL has a non-linear relationship. Considering the non-linear relationship between $\mathrm{TG} / \mathrm{HDL}$ and insulin resistance, we also use the generalized additive and smooth curves to solve the nonlinear problem. Besides, two binary logistic regression models are used to explain the nonlinearity further. A complex sample univariate Logistic regression analysis was used to assess whether baseline characteristics differed among IR participants. Multivariate logistic regression was used to analyze the relationship between TG/HDL and IR under multiple covariables. Model 1 is not adjusted; Model 2 was adjusted for age, race, 
education, gender, and other factors. Model 3 was also adjusted for biochemical indicators, smoking status, diabetes and hypertension.

\section{Consent to participate}

All participants provided written informed consent, and the study was approved by the NCHS Research Ethics Review Board(https://wwwn.cdc.gov/nchs/nhanes/default.aspx)

\section{Patient and public involvement}

Patients and the public were not involved in developing the study question or measuring the outcome, study design or recruitment, and study's conduct. There are no plans to disseminate the results directly to participants.

\section{Results}

We selected the 2017-2018NHANES database to participate in this study, of which 1810 participants were excluded because they did not have HDL results, then 1034 participants were excluded because they did have basic biochemical test results. Finally, 4499 participants were excluded because they did not have insulin test results or BMI information. A total of 1,902 participants were enrolled in the study.囚Figure 1区

Of the 1,902 eligible subjects, we divided them into two groups based on whether they developed insulin resistance. Four hundred fifty subjects with an IR value greater than 4.4 were assigned to the exposed group, and the remaining 1,452 subjects were assigned to the unexposed group. The age of the exposed group and the unexposed group were $53.19 \pm 16.80$ and $50.42 \pm 17.79$, respectively, and the difference in age distribution between the two groups was statistically significant $(P<0.001)$. BMl of the exposed group was higher than that of the unexposed group, and there was statistical significance $(P<0.001)$. There was statistical significance in the race, smoking, waist circumference, hypertension, diabetes, and biochemical indexes such as ALT, ALP, BUN and other conventional biochemical indexes between the two groups $(P<0.001)$. There was no statistical significance in annual income, marriage or gender $(P<0.005) .8 T a b l e 1 \rrbracket$

It showed the relationship between insulin resistance and sex, smoking, education and diabetes mellitus and hypertension. Using men as the baseline, the risk of insulin resistance in women was reduced by $15 \%, P=$ 0.1246 , because $P>0.05$ was not statistically significant. Based on recent non-smoking, the risk of recent smoking and recent non-smoking increased by $112 \%$ and $43 \%$, respectively, $\mathrm{P}<0.0001$, which was statistically significant. Participants with higher education had a $47 \%$ lower risk of developing insulin resistance than those without higher education $(P<0.0001)$, which was statistically significant. The risk of insulin resistance without hypertension and diabetes was reduced by $52 \%$ and $79 \%$, respectively, with statistical significance $(P<0.0001)$. \table 2》

In the study, a total of 450 participants (40\%) developed insulin resistance. A multivariate logistic regression model was used to analyze the association between TG/HDL-C and insulin resistance risk. After adjusting for age, gender, BMI, waist circumference, smoking and other factors, the probability of insulin resistance increased with the increase of TG/HDL ratio (OR: 1.91, 95\% Cl: 1.59-2.30, $\mathrm{P}<0.0001)$. At the same time, we 
conducted a smoothing curve fitting. We found a non-linear relationship between TG/HDL and IR Even when the adjusted covariable was deleted from the model, and the correlation remained unchanged. The inflexion point of TG/HDL-C smoothing curve was 0.95 . When TG/HDL-C $<0.95$, the effect value was very significant (OR: $27.34,95 \% \mathrm{Cl}, 10.61-70.47, \mathrm{P}<0.0001$ ), and when $\mathrm{TG} / \mathrm{HDL}-\mathrm{C} \geq 0.95$, the effect value was relatively lower (OR: $1.29,95 \% \mathrm{Cl}, 1.03-1.61, \mathrm{P}<0.0001)$. We grouped them by inflexion points, and multiple regression equations showed a two-fold increase in the risk of developing insulin resistance after adjustment for groups greater than 0.95 compared with groups less than 0.95

At the same time, we conducted a smoothing curve fitting. We found that there was a non-linear relationship between TG/HDL and IR. Even when the adjusted covariable was deleted from the model, the correlation remained unchanged. The inflexion point of TG/HDL-C smoothing curve was 0.95 . When TG/HDL-C $<0.95$, the effect value was very significant (OR: $27.34,95 \% \mathrm{Cl}, 10.61-70.47, \mathrm{P}<0.0001$ ), and when TG/HDL-C $\geq 0.95$, the effect value was relatively lower (OR: $1.29,95 \% \mathrm{Cl}, 1.03-1.61, \mathrm{P}<0.0001)$. We grouped them by inflexion points. Multiple regression equations showed a two-fold increase in the risk of developing insulin resistance after adjustment for groups greater than 0.95 compared with groups less than 0.95 .『figure $2 \bigotimes$ table $4 \rrbracket$

Figure 3 showed associations between triglyceride/HDL cholesterol ratio and race, waist circumference, high blood pressure, BMI, diabetes, and ALT. In the non-Hispanic Black population, the increase of TG/HDL ratio had the most significant effect on insulin resistance. In the middle and old age of $42-60$, the probability of insulin resistance increased by $177 \%$ for each increase of TG/HDL ratio by one unit. When waist circumference ranged from 63.2 to 92.3 , the effect value was 2.83 , suggesting that the risk of developing insulin resistance increased by $183 \%$ with each increase of TG/HDL ratio by one unit. Regardless of which factor and which group, TG/HDL-C was significantly associated with the occurrence of insulin resistance.

\section{Discussion}

In this study, we used data from the 2017-2018 National Health and Nutrition Examination Survey to determine a significant correlation between TG/HDL and IR (as measured by HOMA-IR) increased risk in the US population after adjusting for known confounders. After adjusting for potential confounding variables, the high TG/HDL-C ratio was positively correlated with HOMA-IR. The TG/HDL-C ratio in the HOMA-IR index $\geq 4.4$ (IR positive) group was significantly higher than that in the HOMA-IR index < 4.4 (IR negative) group. The results show that the TG/HDL-C ratio is useful in detecting IR occurrence.

The TG/HDL ratio increase mechanism is adipose tissue trap, and only a small part of fatty acids will be retained in IR state (28). Therefore, relatively more free fatty acids will be transported to the liver to make more TG and TG containing very-low-density lipoprotein (VLDL). Also, VLDL-rich TG and HDL cholesterol esters are more likely to exchange with the increase of plasma TG concentration. This action makes THE HIGH-density lipoprotein TG prone to dissimilation. Therefore, IR patients often present high TG, high $\mathrm{TG} / \mathrm{HDL}$, and low HDL. In another study, a high TG/HDL ratio was found to play an essential role in the expansion of atherosclerosis in pre-diabetic and newly diagnosed type 2 diabetics (29). Murguia-Romero et al. examined more than 2,000 healthy young subjects and determined that TG/HDL-C ratios could be used to identify IR and increased cardiometabolic risk. There is also evidence that elevated TG/HDL-C ratio is 
associated with morbidity and mortality associated with atherosclerotic disease and cardiovascular disease $(12,30)$. It also predicts long-term mortality in high-risk patients (31). Therefore, our findings have implications for preventing diabetes, cardiovascular disease, cancer, and other new developments.

Our study adjusted waist circumference for confounders because previous studies have found a close correlation between waist circumference and insulin resistance (32). However, in previous studies, waist circumference and insulin resistance were not significant in younger adults, but only in older adults. Therefore, waist circumference was not a suitable predictor of IR in the population as a whole. In any case, TG and HDL-C are standard clinical parameters. They will be effective IR indicators to assess individual health status, which is of great significance for early intervention of IR and related diseases.

There are several advantages to be noted in this study. First, we used a nationally representative sample, and the general applicability of the results was enhanced. This was not the case in previous studies. Second, this time we included all the factors in the analysis instead of limiting the unique sample in the usual studies, which meant that our results were more representative of the general population. We hoped to show the correlation between TG/HDL-C and insulin resistance in the United States' general population, rather than in a specific population. After controlling for all other confounding effects, we hoped to derive an auxiliary effect representing the relationship between TG/HDL-C alone and insulin resistance.

However, there are still some deficiencies in this study. First, our data are derived from cross-sectional surveys; Therefore, further research is needed to explore the association's longitudinal context. Secondly, HOMA-IR has been used as an alternative method to diagnose IR, and its repeatability and reliability have certain limitations. Finally, we did not assess the genetic contribution to disease development, independent of TG/HDL.

\section{Conclusion}

To sum up, in the United States' general population, TG/HDL-C ratio is significantly correlated with insulin resistance under any circumstances. The correlation between TG/HDL-C ratio and insulin resistance seems to increase with the increase of TG/HDL-C ratio. In clinical practice, the significant correlation between TG/ HDL-C ratio and insulin resistance can be well used as an important predictor of morbidity and mortality related to diabetes and cardiovascular diseases and as a basis for the prevention of diabetes and cardiovascular diseases.

\section{Abbreviations}

TG/HDL-C邓triglyceride/ high-density lipoprotein

IR囚insulin resistance Cl: confidence interval OR: odds ratio

BMI囚body mass index; BUN, blood urea nitrogen;LDH,Lactate dehydrogenase;TBIL,total bilirubin;TG,Triglyceride;HDL,high-density lipoprotein ALT: Alanine aminotransferase

ALP: alkaline phosphatase AST: Aspartate aminotransferase 


\section{Declarations}

\section{Authors' contributions}

Rongpeng Gong and Xiaoxing Wei conceived the idea; Rongpeng Gong and Ya Liu wrote the manuscript; Zheng Li and Lixin Yang collected and read the literature and revised the article; Xiaoxing Wei read through and corrected the manuscript. All authors read and approved the final manuscript. Rongpeng Gong is the first author and Xiaoxing Wei is the corresponding author of this paper

\section{Author details}

Rongpeng Gong and Xiaoxing Wei are from Medical College of Qinghai University, Xining 810016, P. R. China.

Zheng Li and Lixin Yang are from Endocrinology Department of Qinghai Provincial People's Hospital. 810016, P. R. China.

\section{Competing interests}

The authors declare that they have no competing interests.

\section{Availability of data and materials}

Not applicable.

\section{Consent for publication}

Not applicable

\section{Ethics approval and consent to participate}

All participants provided written informed consent, and the study was approved by the NCHS Research Ethics Review Board(https://wwwn.cdc.gov/nchs/nhanes/default.aspx)

\section{Funding}

This work was Supported by Grants from National Natural Science Foundation of China (81860370), General Project of Natural Science Foundation of Qinghai Province (2020-ZJ-930) and CAS "Light of West China" Program.

\section{Acknowledgements}

Not applicable

\section{References}


1. WELSH P., PREISS D., LLOYD S. M., DE CRAEN A. J., JUKEMA J. W., WESTENDORP R. G. et al. Contrasting associations of insulin resistance with diabetes, cardiovascular disease and all-cause mortality in the elderly: PROSPER long-term follow-up, Diabetologia 2014: 57: 2513-2520.

2. BIGAZZI R., BIANCHI S., BUONCRISTIANI E., CAMPESE V. M. Increased cardiovascular events in hypertensive patients with insulin resistance: a 13-year follow-up, Nutr Metab Cardiovasc Dis 2008: 18: 314-319.

3. PERSEGHIN G., CALORI G., LATTUADA G., RAGOGNA F., DUGNANI E., GARANCINI M. P. et al. Insulin resistance/hyperinsulinemia and cancer mortality: the Cremona study at the 15th year of follow-up, Acta Diabetol 2012: 49: 421-428.

4. PEPLIES J., BÖRNHORST C., GÜNTHER K., FRATERMAN A., RUSSO P., VEIDEBAUM T. et al. Longitudinal associations of lifestyle factors and weight status with insulin resistance (HOMA-IR) in preadolescent children: the large prospective cohort study IDEFICS, Int J Behav Nutr Phys Act 2016: 13: 97.

5. MUNIYAPPA R., LEE S., CHEN H., QUON M. J. Current approaches for assessing insulin sensitivity and resistance in vivo: advantages, limitations, and appropriate usage, Am J Physiol Endocrinol Metab 2008: 294: E15-26.

6. DEFRONZO R. A., TOBIN J. D., ANDRES R. Glucose clamp technique: a method for quantifying insulin secretion and resistance, Am J Physiol 1979: 237: E214-223.

7. KESKIN M., KURTOGLU S., KENDIRCI M., ATABEK M. E., YAZICI C. Homeostasis model assessment is more reliable than the fasting glucose/insulin ratio and quantitative insulin sensitivity check index for assessing insulin resistance among obese children and adolescents, Pediatrics 2005: 115: e500-503.

8. LEWIS G. F., UFFELMAN K. D., SZETO L. W., STEINER G. Effects of acute hyperinsulinemia on VLDL triglyceride and VLDL apoB production in normal weight and obese individuals, Diabetes 1993: 42: 833842 .

9. VAN LINTHOUT S., SPILLMANN F., SCHULTHEISS H. P., TSCHÖPE C. High-density lipoprotein at the interface of type 2 diabetes mellitus and cardiovascular disorders, Curr Pharm Des 2010: 16: 1504-1516.

10. MCLAUGHLIN T., ABBASI F., CHEAL K., CHU J., LAMENDOLA C., REAVEN G. Use of metabolic markers to identify overweight individuals who are insulin resistant, Ann Intern Med 2003: 139: 802-809.

11. MCLAUGHLIN T., REAVEN G., ABBASI F., LAMENDOLA C., SAAD M., WATERS D. et al. Is there a simple way to identify insulin-resistant individuals at increased risk of cardiovascular disease?, Am J Cardiol 2005: 96: 399-404.

12. BITTNER V., JOHNSON B. D., ZINEH I., ROGERS W. J., VIDO D., MARROQUIN O. C. et al. The triglyceride/high-density lipoprotein cholesterol ratio predicts all-cause mortality in women with suspected myocardial ischemia: a report from the Women's Ischemia Syndrome Evaluation (WISE), Am Heart J 2009: 157: 548-555.

13. CORDERO A., LACLAUSTRA M., LEÓN M., CASASNOVAS J. A., GRIMA A., LUENGO E. et al. Comparison of serum lipid values in subjects with and without the metabolic syndrome, Am J Cardiol 2008: 102: 424-428.

14. DI BONITO P., MOIO N., SCILLA C., CAVUTO L., SIBILIO G., SANGUIGNO E. et al. Usefulness of the high triglyceride-to-HDL cholesterol ratio to identify cardiometabolic risk factors and preclinical signs of 
organ damage in outpatient children, Diabetes Care 2012: 35: 158-162.

15. FAN X., LIU E. Y., HOFFMAN V. P., POTTS A. J., SHARMA B., HENDERSON D. C. Triglyceride/high-density lipoprotein cholesterol ratio: a surrogate to predict insulin resistance and low-density lipoprotein cholesterol particle size in nondiabetic patients with schizophrenia, J Clin Psychiatry 2011: 72: 806-812.

16. GAZIANO J. M., HENNEKENS C. H., O'DONNELL C. J., BRESLOW J. L., BURING J. E. Fasting triglycerides, high-density lipoprotein, and risk of myocardial infarction, Circulation 1997: 96: 2520-2525.

17. GIANNINI C., SANTORO N., CAPRIO S., KIM G., LARTAUD D., SHAW M. et al. The triglyceride-to-HDL cholesterol ratio: association with insulin resistance in obese youths of different ethnic backgrounds, Diabetes Care 2011: 34: 1869-1874.

18. HE S., WANG S., CHEN X., JIANG L., PENG Y., LI L. et al. Higher ratio of triglyceride to high-density lipoprotein cholesterol may predispose to diabetes mellitus: 15-year prospective study in a general population, Metabolism 2012: 61: 30-36.

19. LI C., FORD E. S., MENG Y. X., MOKDAD A. H., REAVEN G. M. Does the association of the triglyceride to high-density lipoprotein cholesterol ratio with fasting serum insulin differ by race/ethnicity?, Cardiovasc Diabetol 2008: 7: 4.

20. MUSSO C., GRAFFIGNA M., SOUTELO J., HONFI M., LEDESMA L., MIKSZTOWICZ V. et al. Cardiometabolic risk factors as apolipoprotein B, triglyceride/HDL-cholesterol ratio and C-reactive protein, in adolescents with and without obesity: cross-sectional study in middle class suburban children, Pediatr Diabetes 2011: 12: 229-234.

21. QUIJADA Z., PAOLI M., ZERPA Y., CAMACHO N., CICHETTI R., VILLARROEL V. et al. The triglyceride/HDLcholesterol ratio as a marker of cardiovascular risk in obese children; association with traditional and emergent risk factors, Pediatr Diabetes 2008: 9: 464-471.

22. ZOPPINI G., NEGRI C., STOICO V., CASATI S., PICHIRI I., BONORA E. Triglyceride-high-density lipoprotein cholesterol is associated with microvascular complications in type 2 diabetes mellitus, Metabolism 2012: 61: 22-29.

23. JOHNSON C. L., PAULOSE-RAM R., OGDEN C. L., CARROLL M. D., KRUSZON-MORAN D., DOHRMANN S. M. et al. National health and nutrition examination survey: analytic guidelines, 1999-2010, Vital Health Stat 2 2013: 1-24.

24. SUN X., DU T. Trends in cardiovascular risk factors among US men and women with and without diabetes, 1988-2014, BMC Public Health 2017: 17: 893.

25. HORNE D. J., CAMPO M., ORTIZ J. R., OREN E., ARENTZ M., CROTHERS K. et al. Association between smoking and latent tuberculosis in the US population: an analysis of the National Health and Nutrition Examination Survey, PLoS One 2012: 7: e49050.

26. JACINTO T., MALINOVSCHI A., JANSON C., FONSECA J., ALVING K. Differential effect of cigarette smoke exposure on exhaled nitric oxide and blood eosinophils in healthy and asthmatic individuals, $J$ Breath Res 2017: 11: 036006.

27. KIM J. S., KANG H. T., SHIM J. Y., LEE H. R. The association between the triglyceride to high-density lipoprotein cholesterol ratio with insulin resistance (HOMA-IR) in the general Korean population: based 
on the National Health and Nutrition Examination Survey in 2007-2009, Diabetes Res Clin Pract 2012: 97: 132-138.

28. KOLOVOU G. D., ANAGNOSTOPOULOU K. K., COKKINOS D. V. Pathophysiology of dyslipidaemia in the metabolic syndrome, Postgrad Med J 2005: 81: 358-366.

29. SCICALI R., GIRAL P., D'ERASMO L., CLUZEL P., REDHEUIL A., DI PINO A. et al. High TG to HDL ratio plays a significant role on atherosclerosis extension in prediabetes and newly diagnosed type 2 diabetes subjects, Diabetes Metab Res Rev 2020: e3367.

30. LARA M., BUSTOS P., AMIGO H., SILVA C., RONA R. J. Is waist circumference a better predictor of blood pressure, insulin resistance and blood lipids than body mass index in young Chilean adults?, BMC Public Health 2012: 12: 638.

31. SULTANI R., TONG D. C., PEVERELLE M., LEE Y. S., BARADI A., WILSON A. M. Elevated Triglycerides to High-Density Lipoprotein Cholesterol (TG/HDL-C) Ratio Predicts Long-Term Mortality in High-Risk Patients, Heart Lung Circ 2020: 29: 414-421.

32. GAUTIER A., ROUSSEL R., DUCLUZEAU P. H., LANGE C., VOL S., BALKAU B. et al. Increases in waist circumference and weight as predictors of type 2 diabetes in individuals with impaired fasting glucose: influence of baseline BMI: data from the DESIR study, Diabetes Care 2010: 33: 1850-1852.

\section{Tables}


Table 1. Baseline characteristics of the study participants

\section{Characteristics \\ All participants \\ $\square \mathrm{N}=1902$ )}

\section{Demographic}

Age(years), mean $\pm S D$

$51.08 \pm 17.59$

Patients with Insulin

resistance $(\mathrm{N}=450)$

Patients without Insulin

resistance $(\mathrm{N}=1452)$

$P$ value

sex

male,no.(\%)

$\mathrm{BMI}(\mathrm{kg} / \mathrm{m} 2), \mathrm{mean} \pm \mathrm{SD}$

$29.73 \pm 7.11$

smoker

never smoker

Current non-smoker,no.

(\%)

Current smoker,no.(\%)

Waist(cm), mean $\pm S D$

race

Mexican American

Other Hispanic

Non-Hispanic White

Non-Hispanic Black

Non-Hispanic Asian

Other Race - Including

Multi-Racial

education, no.(\%)

Less than college, no.

(\%)

College graduate or above, no.(\%)

\section{Clinical characteristics}

\begin{tabular}{|lllll|}
\hline Hypertension, no.(\%) & $667(35.07 \%)$ & $218(48.44 \%)$ & $449(30.92 \%)$ & $<0.001$ \\
\hline $\begin{array}{l}\text { Diabetes mellitus, no. } \\
(\%)\end{array}$ & $316(16.61 \%)$ & $162(36.00 \%)$ & $154(10.61 \%)$ & $<0.001$
\end{tabular}

$53.19 \pm 16.80$

$912(47.95 \%)$

990 (52.05\%)

$50.42 \pm 17.79$

0.003

0.124

230 (51.11\%)

$682(46.97 \%)$

$220(48.89 \%)$

770 (53.03\%)

$35.19 \pm 7.22$

$28.03 \pm 6.16$

$<0.001$

$<0.001$

$56(12.44 \%)$

$273(18.80 \%)$

$249(55.33 \%)$

$846(58.26 \%)$

$145(32.22 \%)$

333 (22.93\%)

$114.34 \pm 15.54$

$96.45 \pm 14.99$

$100.69 \pm 16.92$

$86(19.11 \%)$

$167(11.50 \%)$

47 (10.44\%)

$120(8.26 \%)$

167 (8.78\%)

145 (32.22\%)

$530(36.50 \%)$

99 (22.00\%)

$340(23.42 \%)$

$48(10.67 \%)$

$210(14.46 \%)$

$110(5.78 \%)$

25 (5.56\%)

85 (5.85\%)

$<0.001$

$<0.001$

$1438 \otimes 75.60 \% \bigotimes$

$464(24.40 \%)$

$81(18.00 \%)$

$383(26.38 \%)$

\section{Serum biomarkers}




\begin{tabular}{|c|c|c|c|c|}
\hline $\begin{array}{l}\text { Alanine } \\
\text { aminotransferase(IU/L)区 } \\
\text { median } ₫ Q 1-Q 3 \rrbracket\end{array}$ & $17.00(13.00-25.00)$ & $\begin{array}{l}23.00(16.00- \\
34.00)\end{array}$ & $16.00(12.00-23.00)$ & $<0.001$ \\
\hline 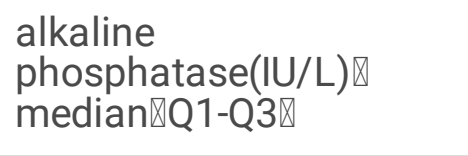 & $74.00(62.00-90.00)$ & $\begin{array}{l}80.00(66.00- \\
96.00)\end{array}$ & $73.00(60.00-88.00)$ & $<0.001$ \\
\hline $\begin{array}{l}\text { Aspartate } \\
\text { aminotransferase(IU/L)》 } \\
\text { median } ₫ Q 1-Q 3 \rrbracket\end{array}$ & $19.00(16.00-24.00)$ & $\begin{array}{l}20.00(16.00- \\
27.00)\end{array}$ & $19.00(16.00-23.00)$ & $<0.001$ \\
\hline $\begin{array}{l}\text { BUN(mmol/L)『median } \\
\text { खQ1-Q3】 }\end{array}$ & $5.00(3.93-6.43)$ & $5.36(4.28-6.43)$ & $5.00(3.93-6.07)$ & $<0.001$ \\
\hline 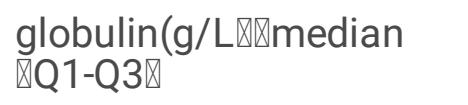 & $31.00(28.00-34.00)$ & $\begin{array}{l}32.00(29.00- \\
35.00)\end{array}$ & $30.00(28.00-33.00)$ & $<0.001$ \\
\hline $\begin{array}{l}\text { Y-glutamyl } \\
\text { transpeptadase }(\mathrm{U} / \mathrm{L}) \bigotimes \\
\text { median囚Q1-Q3》 }\end{array}$ & $21.00(15.00-32.00)$ & $\begin{array}{l}27.00(20.00- \\
43.00)\end{array}$ & $19.00(14.00-29.00)$ & $<0.001$ \\
\hline 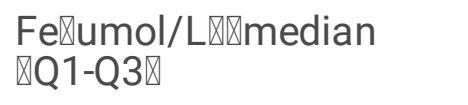 & $15.60(11.60-20.10)$ & $\begin{array}{l}14.50(10.70- \\
18.40)\end{array}$ & $15.90(11.95-20.80)$ & $<0.001$ \\
\hline $\begin{array}{l}\text { TBIL(umol/L)『median } \\
\text { 『Q1-Q3】 }\end{array}$ & $6.84(5.13-10.26)$ & $6.84(5.13-8.55)$ & $8.55(5.13-10.26)$ & $<0.001$ \\
\hline $\begin{array}{l}\text { TG/HDL『median『Q1- } \\
\text { Q3囚 }\end{array}$ & $0.88(0.56-1.40)$ & $1.30(0.92-1.88)$ & $0.77(0.51-1.20)$ & $<0.001$ \\
\hline TG/HDL group & & & & $<0.001$ \\
\hline$<0.95$, no.(\%) & 1019 (54.67\%) & $121(27.25 \%)$ & 898 (63.24\%) & \\
\hline >=0.95, no. $(\%)$ & 845 (45.33\%) & $323(72.75 \%)$ & $522(36.76 \%)$ & \\
\hline
\end{tabular}


Table 2. Univariate analysis for Insulin resistance

\begin{tabular}{|c|c|c|c|}
\hline Covariate & Statistics & OR(95\% Cl) & Pvalue \\
\hline Age(years), mean $\pm S D$ & $51.08 \pm 17.59$ & $1.01(1.00,1.02)$ & 0.0036 \\
\hline $\mathrm{BMI}(\mathrm{kg} / \mathrm{m} 2)$, mean $\pm \mathrm{SD}$ & $29.73 \pm 7.11$ & $\begin{array}{l}1.16(1.14 \\
1.18)\end{array}$ & $<0.0001$ \\
\hline Waist $(\mathrm{cm})$, mean $\pm S D$ & $100.69 \pm 16.92$ & $1.07(1.07,1.08)$ & $<0.0001$ \\
\hline Alanine aminotransferase(IU/L) $₫$ median $₫ \mathrm{Q} 1-\mathrm{Q} 3 \rrbracket$ & $\begin{array}{l}17.00(13.00- \\
25.00)\end{array}$ & $1.03(1.03,1.04)$ & $<0.0001$ \\
\hline alkaline phosphatase(IU/L)『median $\varangle Q 1-Q 3 \rrbracket$ & $\begin{array}{l}74.00(62.00- \\
90.00)\end{array}$ & $1.01(1.01,1.02)$ & $<0.0001$ \\
\hline 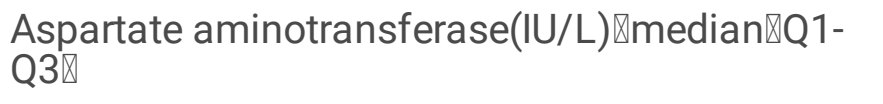 & $\begin{array}{l}19.00(16.00- \\
24.00)\end{array}$ & $1.02(1.01,1.03)$ & $<0.0001$ \\
\hline \multicolumn{4}{|l|}{ sex } \\
\hline male & $912(47.95 \%)$ & 1 & \\
\hline Female & 990 (52.05\%) & $0.85(0.69,1.05)$ & 0.1246 \\
\hline \multicolumn{4}{|l|}{ education } \\
\hline Less than college , no.(\%) & $1438 \rrbracket 75.60 \% \rrbracket$ & 1 & \\
\hline College graduate or above, no.(\%) & $464(24.40 \%)$ & $0.61(0.47,0.80)$ & 0.0003 \\
\hline \multicolumn{4}{|l|}{ smoker } \\
\hline never smoker & $329(17.30 \%)$ & 1 & \\
\hline Current non-smoker,no.(\%) & $1095(57.57 \%)$ & $1.43(1.04,1.98)$ & 0.0272 \\
\hline Current smoker,no.(\%) & $478(25.13 \%)$ & $\begin{array}{l}2.12(1.50 \\
3.00)\end{array}$ & $<0.0001$ \\
\hline
\end{tabular}

TG/HDL『medianヌQ1-Q3》

Hypertension

NO,no.(\%)

$1235(64.93 \%) \quad 1$

YES,no.(\%)

$667(35.07 \%)$

$2.10(1.69,2.60) \quad<0.0001$

Diabetes mellitus, no.(\%)

\begin{tabular}{lccc} 
NO,no.(\%) & $1580(83.39 \%)$ & 1 & \\
Yes,no.(\%) & $316(16.61 \%)$ & $4.74(3.67,6.12)$ & $<0.0001$ \\
\hline TG/HDL group & & & \\
$<0.95$, no.(\%) & $1019(54.67 \%)$ & 1 & \\
$>=0.95$, no.(\%) & $845(45.33 \%)$ & $4.59(3.63,5.81)$ & $<0.0001$
\end{tabular}


Table 3.The association between TG/HDL and insulin resistance in a multiple regression model

\begin{tabular}{|c|c|c|c|c|c|c|}
\hline \multirow[t]{2}{*}{ Outcome } & \multicolumn{2}{|c|}{ Non-adjusted Model } & \multicolumn{2}{|l|}{ Model1 } & \multicolumn{2}{|l|}{ Model2 } \\
\hline & OR(95\%Cl) & P-value & OR(95\%Cl) & $P$-value & OR(95\%Cl) & $P$-value \\
\hline TG/HDL & $\begin{array}{l}2.41(2.09 \\
2.78)\end{array}$ & $<0.0001$ & $\begin{array}{l}2.53(2.17 \\
2.95)\end{array}$ & $<0.0001$ & $\begin{array}{l}1.99 \\
2.38\end{array}$ & $<0.0001$ \\
\hline \multicolumn{7}{|l|}{$\begin{array}{l}\text { TG/HDL } \\
\text { group }\end{array}$} \\
\hline$<0.95$ & 1 & & 1 & & 1 & \\
\hline$>=0.95$ & $\begin{array}{l}4.59(3.63 \\
5.81)\end{array}$ & $<0.0001$ & $\begin{array}{l}4.93(3.83 \\
6.33)\end{array}$ & $<0.0001$ & $\begin{array}{l}3.05(2.29 \\
4.04)\end{array}$ & $<0.0001$ \\
\hline
\end{tabular}

Non-adjusted model adjust for: None.Adjust I model adjust for: Gender; age; race; education. Adjust II model adjust for: BMl; HBP; Wasit; education; smoking; diabetes; ALT(IU/L); ALB(g/L); TBIL(umol/L); ALP(IU/L); Gender; age; BUNखmmol/L); GLB(g/L); GGT(IU/L); Fe(umol/L); TC(mmol/L)

Table 4. Threshold effect analysis of TG/HDL-C on insulin resistance

\section{Outcome}

One-linear regression modle

Two-piecewise linear regression model

TG/HDL-C<0.95

TG/HDL-C0.95

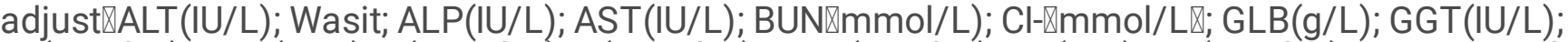

$\mathrm{Fe}(\mathrm{umol} / \mathrm{L}) ; \mathrm{LDH}(\mathrm{IU} / \mathrm{L}) ; \mathrm{P}(\mathrm{mmol} / \mathrm{L}) ; \mathrm{K}(\mathrm{mmol} / \mathrm{L}) ; \mathrm{TBIL}(\mathrm{umol} / \mathrm{L}) ; \mathrm{TP}(\mathrm{g} / \mathrm{L}) ; \mathrm{UA}(\mathrm{umol} / \mathrm{L}) ;$ age; race; education; smoking; diabetes; BMl; HBP

\section{Figures}




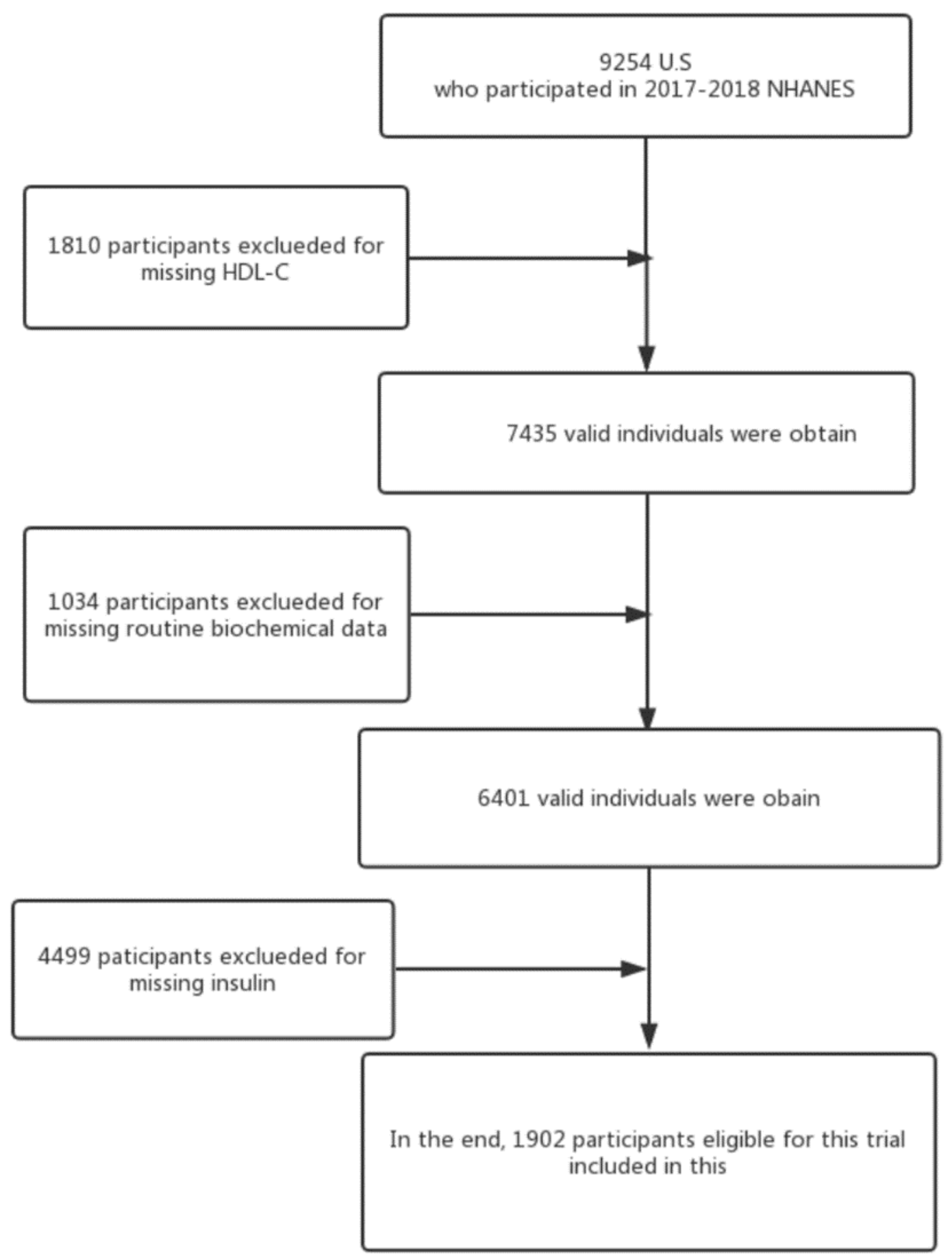

\section{Figure 1}

Flowchart of patient selection. 


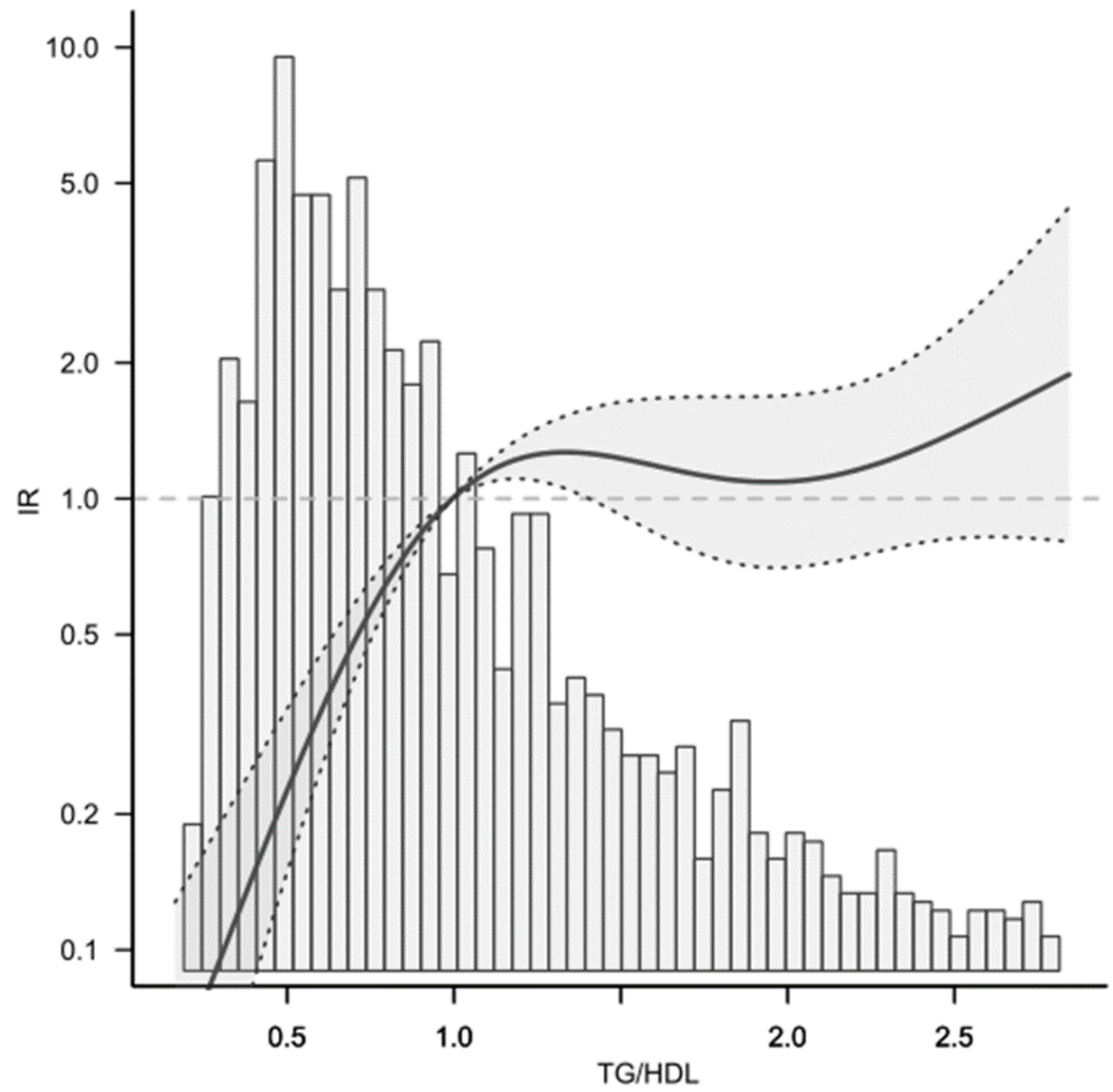

Figure 2

Association between TG/HDL-C and IR. Notes: The two blue lines represent estimates and their corresponding $95 \%$ confidence intervals. 


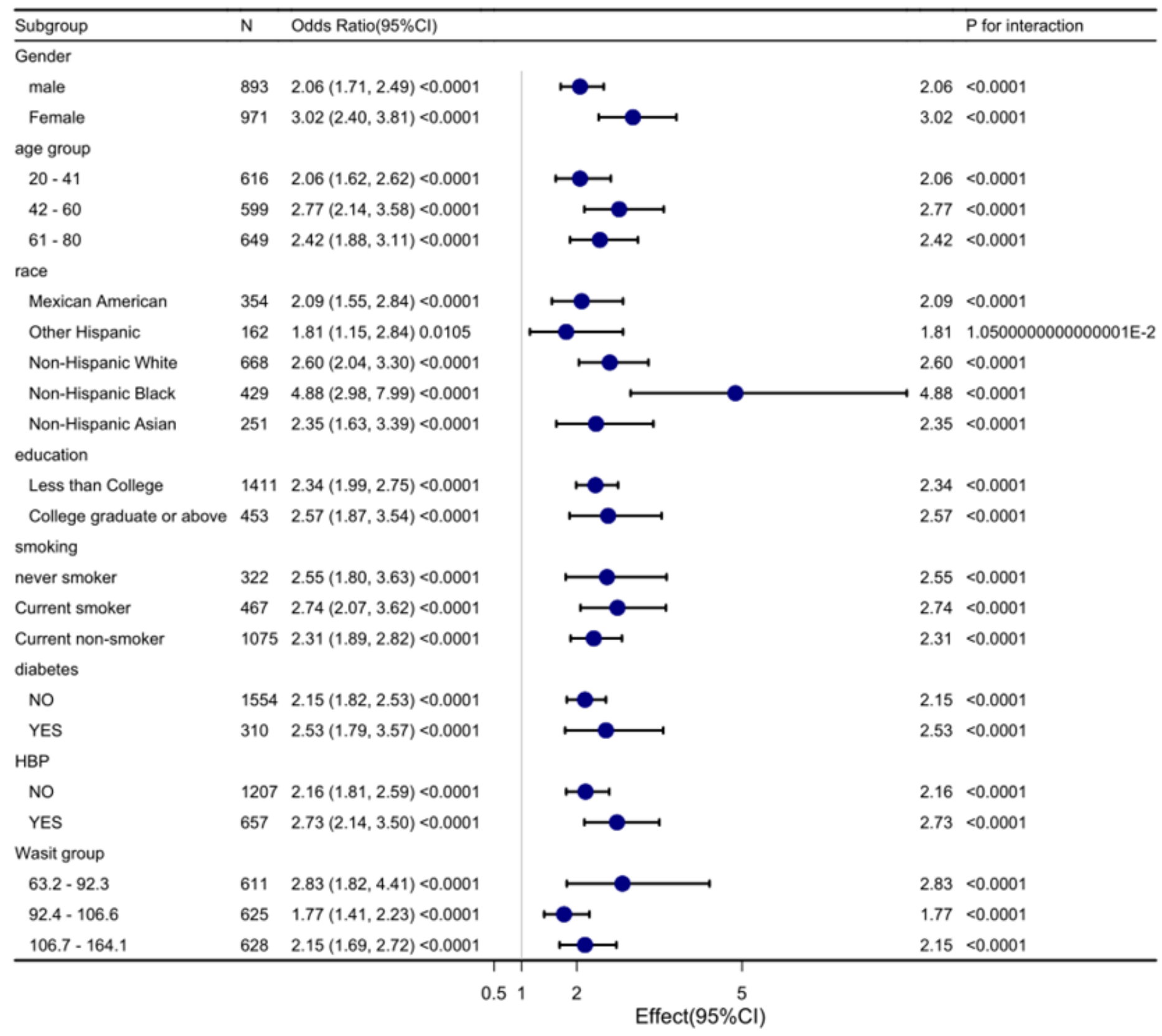

\section{Figure 3}

Association of triglycerides to high-density lipoprotein-cholesterol ratio with risk of incident 